\title{
Association of immunological features with COVID- 19 severity: a systematic review and meta-analysis
}

\section{Zhicheng Zhang}

Tongji Hospital of Tongji Medical College of Huazhong University of Science and Technology

\section{Guo Ai}

Tongji Hospital of Tongji Medical College of Huazhong University of Science and Technology

\section{Liping Chen}

Tongji Hospital of Tongji Medical College of Huazhong University of Science and Technology

Shunfang Liu

Tongji Hospital of Tongji Medical College of Huazhong University of Science and Technology

\section{Chen Gong}

Tongji Hospital of Tongji Medical College of Huazhong University of Science and Technology

Xiaodong Zhu

Huang Gang Central Hospital

Chunli Zhang

Huang Gang Central Hospital

Hua Qin

Tongji Hospital of Tongji Medical College of Huazhong University of Science and Technology Junhui Hu

UCLA: University of California Los Angeles

Jinjin Huang ( $\nabla$ zczhang@tjh.tjmu.edu.cn )

Tongji Hospital of Tongji Medical College of Huazhong University of Science and Technology https://orcid.org/0000-0003-1630-0385

Research article

Keywords: COVID-19, Severity, Immune cells, Cytokines, Chemokines Meta-analysis

Posted Date: October 5th, 2020

DOI: https://doi.org/10.21203/rs.3.rs-38914/v2

License: (c) (i) This work is licensed under a Creative Commons Attribution 4.0 International License. Read Full License 
Version of Record: A version of this preprint was published at BMC Infectious Diseases on August 3rd, 2021. See the published version at https://doi.org/10.1186/s12879-021-06457-1. 


\section{Abstract}

Background: We aim to explore the association of immunological features with COVID-19 severity.

Methods: We conducted a meta-analysis to estimate mean difference (MD) of immune cells and cytokines levels with COVID-19 severity in PubMed, Web of Science, Scopus, the Cochrane Library and the grey literature.

Results: A total of 21 studies with 2033 COVID-19 patients were included. Compared with mild cases, severe cases showed significantly lower levels of some immune cells, $\mathrm{CD}^{+} \mathrm{T}$ cell $\left(\times 10^{6}, \mathrm{MD},-413.87\right.$; $95 \% \mathrm{Cl},-611.39$ to -216.34$), \mathrm{CD} 4^{+} \mathrm{T}$ cell $\left(\times 10^{6}, \mathrm{MD},-203.56 ; 95 \% \mathrm{Cl},-277.94\right.$ to -129.18$), \mathrm{CD}^{+} \mathrm{T}$ cell $\left(\times 10^{6}\right.$, MD, $-128.88 ; 95 \% \mathrm{Cl},-163.97$ to -93.79$)$, B cell $\left(\times 10^{6} / \mathrm{L} ; \mathrm{MD},-23.87 ; 95 \% \mathrm{Cl},-43.97\right.$ to -3.78$)$ and $\mathrm{NK}$ cell $\left(\times 10^{6} / \mathrm{L} ; \mathrm{MD},-57.12 ; 95 \% \mathrm{Cl},-81.18\right.$ to -33.06$)$, and significantly higher levels of some cytokines, TNF-a ( $\mathrm{pg} / \mathrm{ml} ; \mathrm{MD}, 0.34 ; 95 \% \mathrm{Cl}, 0.09$ to 0.59 ), IL-5 (pg/ml; MD, 14.2; $95 \% \mathrm{Cl}, 3.99$ to 24.4 ), IL-6 (pg/ml; MD, 13.07; $95 \% \mathrm{Cl}, 9.80$ to 16.35$)$, and IL-10 (pg/ml; MD, $2.04 ; 95 \% \mathrm{Cl}, 1.32$ to 2.75$)$, and significantly higher levels of some chemokines, MCP-1 (SMD, 3.41; 95\% Cl, 2.42 to 4.40), IP-10 (SMD, 2.82; 95\% $\mathrm{Cl}, 1.20$ to 4.45 ) and eotaxin (SMD, 1.55; 95\% Cl, 0.05 to 3.05). However, no significant differences were found in other indicators, Treg cell $\left(\times 10^{6}, \mathrm{MD},-0.13 ; 95 \% \mathrm{Cl},-1.40\right.$ to 1.14$), \mathrm{CD}^{+} / \mathrm{CD}^{+}$ratio $(\mathrm{MD}, 0.26 ; 95 \% \mathrm{Cl},-0.02$ to 0.55 ), IFN-y (pg/ml; MD, $0.26 ; 95 \% \mathrm{Cl},-0.05$ to 0.56 ), IL-2 (pg/ml; MD, $0.05 ; 95 \% \mathrm{Cl},-0.49$ to 0.60 ), IL-4 (pg/ml; MD, $-0.03 ; 95 \% \mathrm{Cl},-0.68$ to 0.62 ), GM-CSF (SMD, $0.44 ; 95 \% \mathrm{Cl},-0.46$ to 1.35 ), and RANTES (SMD, $0.94 ; 95 \% \mathrm{Cl},-2.88$ to 4.75$)$.

Conclusion: Our meta-analysis revealed significant lower levels of immune cells ( $C D 3^{+} \mathrm{T}, \mathrm{CD} 4^{+} \mathrm{T}, \mathrm{CD} 8^{+} \mathrm{T}$, $B$ and NK cells), significant higher levels of cytokines (TNF-a, IL-5, IL-6 and IL-10) and significant higher levels of chemokines (MCP-1, IP-10 and eotaxin) in severe cases compared with mild cases of COVID-19. Measurement of immunological features could help to assess disease severity for effective triage of COVID-19 patients.

\section{Background}

Coronavirus disease 2019 (COVID-19) caused by severe acute respiratory syndrome coronavirus 2 (SARSCoV-2) infection has been spreading all over the world [1]. Till September 09, 2020, the SARS-CoV-2 has infected over 27 million patients and caused over 890,000 deaths [2]. The severity of COVID-19 may be strongly related to immune status of patients, but this is poorly understood. Therefore, it is necessary to explore the association of immunological features with COVID-19 severity, which may help to identify immune markers of disease severity for effective triage of COVID-19 patients.

Some studies focused on the association between immunologic features and COVID-19 severity, but the conclusions remain controversial. Chen et al. found that the SARS-CoV-2 infection may decrease primarily $\mathrm{T}$ lymphocytes, particularly $\mathrm{CD} 4^{+}$and $\mathrm{CD} 8^{+} \mathrm{T}$ cells [3]. Qin et al. showed that the increase in cytokines levels (tumor necrosis factor alpha (TNF-a), interleukin-5 (IL-5), IL-6 and IL-10) correlated with 
COVID-19 course, especially in severe cases [4]. Sophie et al. demonstrated that increased serum concentrations of IFN- $y$ inducible protein-10 (IP-10/CXCL10) and granulocyte-macrophage colonystimulating factor (GM-CSF) were associated with day-28 mortality of COVID-19 patients [5]. However, other studies have revealed that $\mathrm{CD} 4^{+}$and $\mathrm{CD} 8^{+} \mathrm{T}$ cell [4], some cytokines (IL-5, IL-6 and IL-10) [6] and some chemokines (GM-CSF and IP-10) [7] showed no significant differences between severe cases and mild cases. Thus, we presented a meta-analysis of 21 studies in order to assess the association between immune cells ( $C D 4^{+} \mathrm{T}, \mathrm{CD} 8^{+} \mathrm{T}, \mathrm{CD} 3^{+} \mathrm{T}$, Treg, $\mathrm{B}$ and NK cells), cytokines (TNF- $\mathrm{a}$, interferon gamma (IFN- $\gamma$ ), IL-2, IL-4, IL-5, IL-6 and IL-10), chemokines (GM-CSF, RANTES, MCP-1, IP-10 and eotaxin) and COVID-19 severity respectively.

\section{Methods}

\section{Search Strategy}

We performed a systematic literature search to identify relevant studies published up to September 09, 2020 in PubMed, Web of Science, Scopus, the Cochrane Library and the grey literature. The following combined search terms were used: ("Novel coronavirus" OR "Coronavirus disease 2019" OR "Coronavirus 2019" OR "nCoV-2019" OR "2019-nCoV" OR "COVID-19" OR "SARS-CoV-2") and (("CD3+ T" OR "CD4+ T" OR "CD8+ T" OR "CD4+/CD8+" OR "Treg" OR "B cell" OR "NK cell") OR ("interferon gamma" OR "tumor necrosis factor alpha" OR "IL-2" OR "IL-4" OR "IL-5" OR "IL-6" OR "IL-10") OR ("chemokine" OR "chemokines" OR "RANTES" OR "GM-CSF" OR "Eotaxin" OR "MCP-1" OR "IP-10")).

\section{Study selection}

Inclusion criteria of the study were as follows: 1$)$ studies with data on immune cells (CD4 ${ }^{+} \mathrm{T}, \mathrm{CD} 8^{+} \mathrm{T}$, $\mathrm{CD}^{+}{ }^{+} \mathrm{T}, \mathrm{CD} 4^{+} / \mathrm{CD}^{+}{ }^{+}$, Treg, B and NK cells), cytokines (IFN, TNF-a, IL-2, IL-4, IL-5, IL-6 and IL-10) and chemokines (GM-CSF, RANTES, MCP-1, IP-10 and eotaxin) with mean \pm standard deviation (SD) or median (interquartile range, IQR); 2) patients could be grouped into severe cases and mild cases; and 3 ) studies with clear information on COVID-19 confirmation and included patients. And exclusion criteria were as follows: 1) studies without corresponding outcome of indicators; 2) studies without available full texts; 3) studies not published in English; 4) lack of mean \pm SD or mean (IQR) of indicators; 5) reviews, editorials, case reports, and meta-analysis.

Two investigators developed the search strategy and one investigator conducted the primary systematic search for all studies meeting the predetermined inclusion criteria. The titles and abstracts of the retrieved articles were screened for duplicates and relevance to the topic. A second investigator checked study eligibility, quality assessment, and data extraction, for validity and consistency. Full-text reports of the identified citations were reviewed by both the primary and secondary investigators in order to select the final studies. Any discrepancy was resolved by consensus, and if necessary, by consultation with the third investigator.

\section{Data extraction}


The following data were extracted from each study: 1) the first author and year of publication; 2) study design; 3 ) the country where the study was conducted; 4) ages; 5) sample size; 6) sex; 7) the levels of immune cells ( $\mathrm{CD} 4^{+} \mathrm{T}, \mathrm{CD} 8^{+} \mathrm{T}, \mathrm{CD} 3^{+} \mathrm{T}, \mathrm{CD}^{+} / \mathrm{CD} 8^{+}$, Treg, B and NK cells), and cytokines (IFN, TNF-a, IL-2, IL-4, IL-5, IL-6 and IL-10), and chemokines (GM-CSF, RANTES, MCP-1, IP-10 and eotaxin). Median (IQR) were converted to mean \pm SD using mathematical formulas according to Hozo et al [8].

\section{Quality assessment}

Quality assessments of the studies were carried out based on the Newcastle-Ottawa Scale (NOS). The total NOS score $\geq 7$ indicated a good research quality of the included study.

\section{Data synthesis and analysis}

Data entry and analysis were carried out with Review Manager 5.3 (The Cochrane Collaboration, Oxford, England). Heterogeneity of effect estimates within each group of studies were assessed by Q test and $R$ statistic, where $R^{2}>50 \%$ or $p<0.05$ indicated heterogeneity and the random-effects model was used. When $R^{2} \leq 50 \%$ or $p \geq 0.05$, the fixed-effects model was used. For continuous data, we calculated mean differences (MD) and 95\% confidence intervals (Cl) between severe cases and mild cases. To investigate the potential publication bias, we visually examined the funnel plots. For robustness of results, we performed sensitivity analysis by removing one study each time through sensitivity analysis.

\section{Results}

\section{Search results and characteristics of included studies}

Fig 1 provides the flow diagram for study selection. Based on the inclusion criteria, 75 full articles were retrieved and 21 of these were included in the final meta-analysis. Duplicate publications, reviews, editorials, case reports, and studies without median (IQR) and mean \pm SD of indicators were excluded. Table 1 presents the characteristics of the 21 included studies, with 758 severe cases and 1275 mild cases of COVID-19 reported. All but one prospective study [9] of the studies included in this meta-analysis were retrospective studies, which were mostly performed in China. All studies were deemed of high quality with 7 or more NOS scores and details can be found in Table 2 .

\section{Association of immune cells with COVID-19 severity}

Compared with mild cases, severe cases showed significantly lower levels of some immune cells, $\mathrm{CD}^{+} \mathrm{T}$ cell $\left(\times 10^{6}, \mathrm{MD},-413.87 ; 95 \% \mathrm{Cl},-611.39\right.$ to $-216.34 ; R^{2}, 100 \% ; p<0.001$, Fig $\left.2 \mathrm{a}\right), \mathrm{CD} 4^{+} \mathrm{T}$ cell $\left(\times 10^{6}, \mathrm{MD}\right.$, $-203.56 ; 95 \% \mathrm{Cl},-277.94$ to $-129.18 ; P^{2}, 99 \% ; p<0.001$, Fig $\left.2 \mathrm{~b}\right), \mathrm{CD}^{+} \mathrm{T}$ cell $\left(\times 10^{6}, \mathrm{MD},-128.88 ; 95 \% \mathrm{Cl}\right.$, -163.97 to $-93.79 ; I^{2}, 99 \% ; p<0.001$, Fig 2 c), B cell $\left(\times 10^{6} / \mathrm{L} ; \mathrm{MD},-23.87 ; 95 \% \mathrm{Cl},-43.97\right.$ to $-3.78 ; I^{2}, 87 \% ; p<$ 0.001 , Fig 2f), and NK cell ( $\times 10^{6} / \mathrm{L} ; \mathrm{MD},-57.12 ; 95 \% \mathrm{Cl},-81.18$ to $-33.06 ; \ell^{2}, 92 \% ; p<0.001$, Fig $\left.2 \mathrm{~g}\right)$. However, no significant differences were found in other indicators, $\mathrm{CD} 4^{+} / \mathrm{CD} 8^{+}$ratio $(\mathrm{MD}, 0.26 ; 95 \% \mathrm{Cl}$, 
-0.02 to $0.55 ; I^{2}, 97 \% ; p<0.001$, Fig $\left.2 \mathrm{~d}\right)$ and Treg cell $\left(\times 10^{6}, \mathrm{MD},-0.13 ; 95 \% \mathrm{Cl},-1.40\right.$ to $1.14 ; I^{2}, 90 \% ; p=$ 0.002 , Fig 2e).

\section{Association of cytokines with COVID-19 severity}

Compared with mild cases, severe cases showed significantly higher levels of some cytokines, TNF-a (pg/ml; MD, 0.34; 95\%Cl, 0.09 to 0.59; $P^{2}, 98 \% ; p<0.001$, Fig 2h), IL-5 (pg/ml; MD, 14.20; 95\%Cl, 3.99 to $24.4 ; P^{2}, 99 \% ; p<0.001$, Fig 2l), IL-6 (pg/ml; MD, 13.07; 95\%Cl, 9.80 to $16.35 ;{ }^{2}, 100 \% ; p<0.001$, Fig $2 \mathrm{~m}$ ), and IL-10 (pg/ml; MD, 2.04; $95 \% \mathrm{Cl}, 1.32$ to $2.75 ; R, 99 \% ; p<0.001$, Fig $2 \mathrm{n}$ ). However, there were no significant differences found in other cytokines, IFN- $\mathrm{Y}(\mathrm{pg} / \mathrm{ml} ; \mathrm{MD}, 0.26 ; 95 \% \mathrm{Cl},-0.05$ to $0.56 ; R, 98 \% ; p<$ 0.001 , Fig 2i), IL-2 (pg/ml; MD, 0.05; $95 \% \mathrm{Cl},-0.49$ to $0.6 ; P^{2}, 100 \% ; p<0.001$, Fig 2j), and IL-4 (pg/ml; MD, $-0.03 ; 95 \% \mathrm{Cl},-0.68$ to $0.62 ; P^{2}, 100 \% ; p<0.001$, Fig $2 \mathrm{k}$ ).

\section{Association of chemokines with COVID-19 severity}

Compared with mild cases, severe cases showed significantly higher levels of some chemokines, MCP-1 (SMD, 3.41; 95\%Cl, 2.42 to $4.40 ; r^{2}, 71 \% ; p=0.03$, Fig $2 q$ ), IP-10 (SMD, $2.82 ; 95 \% \mathrm{Cl}, 1.20$ to $4.45 ;{ }^{2}, 91 \% ; p$ $<0.001$, Fig 2 r), and eotaxin (SMD, $1.55 ; 95 \% \mathrm{Cl}, 0.05$ to $3.05 ; l^{2}, 87 \% ; p=0.01$, Fig $2 \mathrm{~s}$ ). However, there were no significant differences found in other chemokines, GM-CSF (SMD, $0.44 ; 95 \% \mathrm{Cl},-0.46$ to $1.35 ; l^{2}, 85 \% ; p$ $=0.001$, Fig 20) and RANTES (SMD, $0.94 ; 95 \% \mathrm{Cl},-2.88$ to $4.75 ;{ }^{2}, 98 \% ; p<0.001$, Fig $2 p$ ).

\section{Sensitivity Analysis}

Strong evidences of heterogeneity were found in all the comparisons (Fig 2). Sensitivity analyses showed that tour results were not obviously impacted by excluding any one specific study for "CD4+ T", "CD8+ T", “CD3+ T”, “CD4+/CD8+”, “Treg”, “B cell”, “NK cell”, “TNF-a” “IFN”, “IL-2”, “IL-4”, “IL-5”, “IL-6”, “IL-10”, "RANTES", "MCP-1", "IP-10" and "eotaxin" between the severe group and the mild group. But after excluding the study Chi et al. [24]on GM-CSF (SMD, 0.94; 95\%Cl, 0.58 to1.31), the sensitivity findings showed that there was a significant difference between pre- and post-sensitivity pooled SMD on its outcome, suggesting that it is better to keep this result in the meta-analysis. Hence, our sensitivity analysis indicates that most of our results are reliable and believable.

\section{Publication bias}

We assessed the publication bias of the literature by the funnel plots in all included studies of each indicator, respectively. Funnel plot analysis did not detect obvious publication bias as the shape of all funnel plots did not reveal any evidence of obvious asymmetry (Fig 3 ).

\section{Discussion}

It is necessary to explore the host immune response to SARS-CoV-2, which may help to identify immune markers of disease severity for effective triage of COVID-19 patients [25]. Our study mainly compared the 
level differences of immune cells, cytokines and chemokines between mild and severe patients with COVID-19.

The variations of immune cells levels are inconsistent in different reports. Most of our included studies found significant lower levels of immune cells ( $C D 8^{+} \mathrm{T}, \mathrm{CD} 4^{+} \mathrm{T}, \mathrm{CD} 3^{+} \mathrm{T}, \mathrm{B}$ and NK cells) in severe cases compared with mild cases $[3,11,15]$. Only two studies reported no significant decrease in $\mathrm{CD}^{+} \mathrm{T}$ cell level $[4,19]$, while one study reported higher levels of B cell [14] in severe cases. Synthesizing all the collected evidence, our meta-analysis results found that the levels of immune cells (CD8+ T, CD4+ T, CD3+ $\mathrm{T}, \mathrm{B}$ and NK cells) were significantly lower in severe cases compared with mild cases, but Treg cell level and $\mathrm{CD} 4^{+} / \mathrm{CD} 8^{+}$ratio showed no significant differences.

The mechanism underlying the association between the reduction of immune cells levels and COVID-19 severity remain to be determined. $C D 8^{+} T$ cells exert their effects mainly through two mechanisms, including cytolytic activities against target cells and secretion of cytokines [20]. CD $4^{+} T$ cells could activate the $\mathrm{CD} 8^{+} \mathrm{T}$ cell response to acute respiratory virus infection [25]. SARS-CoV-2 and associated autoimmune antibodies may lead to growth inhibition and apoptosis of hematopoiesis [26], which may decrease the production and maturation of immune cells [6].

With regard to cytokines, the conclusions of different studies are also inconsistent. With the exception of one study on IL-6 [6] and another study on TNF-a, most of our included studies found that of IL-6 and TNF-a levels were significantly higher in severe cases compared with mild cases $[4,16,20,27]$. Some of our included studies found no significant differences in the levels of IL-2, IL-4, IL-5, and IFN- $\gamma$, while an nearly equivalent number of studies of each indicator found that they were significantly higher in severe cases. Synthesizing all the collected evidence, our meta-analysis results found that IL-5, IL-6, IL-10 and TNF-a levels were significantly higher in severe cases compared with mild cases. However, the levels of IL-2, IL-4, IFN- $y$, Treg cell and $\mathrm{CD} 4^{+} / \mathrm{CD} 8^{+}$ratio showed no significant differences.

In severely infected individuals, SARS-CoV-2 could induce excessive cytokine response, such as IL-6, IL10 , and TNF-a surge, known as cytokine storm. Cytokine storm could contribute to acute respiratory distress syndrome (ARDS) or multiple-organ dysfunction, leading to physiological deterioration and death [28]. Cytokines such as IL-10, IL-6, and TNF- $a$ are also involved in T cell reduction. IL- 6 contributes to host defense via stimulation of acute phase responses [29]. TNF-a is a pro-inflammatory cytokine that can promote T cell apoptosis [30]. Patients requiring ICU admission have significantly higher levels of IL-6, IL10 , and TNF- $a$. Further, the levels of IL- 6 , IL-10, and TNF-a inversely correlate with CD $4^{+}$and $C D 8^{+}$T cell counts [31]. This fact is strengthened by our meta-analysis results.

SARS-CoV-2 infection is a potent inducer of proinflammatory chemokines that may be involved in the defense against viral infections [24]. Some studies reported higher concentrations of GM-CSF [5], IP-10 [5, $23,24]$, MCP-1 [23, 24], eotaxin [7] and RANTES [23] between severe cases and mild cases. However, other studies have not showed significant differences in the concentrations of GM-CSF [7, 24], IP-10 [7], RANTES [24] , MCP-1 [7], and eotaxin [24] . Synthesizing all the collected evidence, our meta-analysis 
results found that MCP-1, IP-10 and eotaxin levels were significantly higher in severe cases compared with mild cases. However, the levels of GM-CSF and RANTES showed no significant differences. Through its binding to the chemokine receptor 3 , IP-10 activates and recruits leucocytes, including T cells and monocytes, thereby perpetuating inflammation [32]. MCP-1-mediated migration of monocytes from the blood stream through the vascular endothelium is essential for routine immune surveillance of tissues, as well as in response to inflammation [33]. Abnormally elevated MCP-1, IP-10 and eotaxin levels may help to determine the severity of SARS-CoV-2 infections and may be predictors of clinical symptoms.

\section{Limitations}

Several limitations of our study should be considered. First, the number of studies and participants was not large enough for publication bias analysis of most indicators. Second, most of the included studies in this meta-analysis were retrospective. Third, the overall generalizability of the meta-analysis results should be interpreted with caution as most of included studies were conducted in China. It would be better to include as many studies with a broad geographic scope, to gain a more comprehensive understanding of immunological features of COVID-19 patients.

\section{Conclusions}

Our synthesized results revealed significant lower levels of immune cells $\left(C D 3^{+} \mathrm{T}, \mathrm{CD} 4^{+} \mathrm{T}, \mathrm{CD} 8^{+} \mathrm{T}\right.$, B and NK cells), significant higher levels of cytokines (TNF-a, IL-5, IL-6 and IL-10) and significant higher levels of chemokines (MCP-1, IP-10 and eotaxin) in severe cases compared with mild cases of COVID-19 patients. However, the levels of Treg cell, CD $4^{+} / \mathrm{CD} 8^{+}$ratio, IL-2, IL-4, IFN-y, GM-CSF and RANTES showed no significant differences. Measurement of immune cells and cytokines may help to identify immune markers of COVID-19 severity and contribute to the development of immunologic therapies and vaccine design of COVID-19.

\section{Declarations}

\section{Acknowledgments}

We thank Yunsheng, Fang, Ph.D (University of California, Los Angeles, California, UCLA) for revision of the manuscript.

\section{Authors' contributions}

Conception: ZZ, HJJ. Literature search: ZZ, HJJ. Selection of studies: ZX, ZC. Full texts search: ZZ, LS. Data extraction: GC. Data synthesis and analysis: ZZ, AG. Data interpretation: CL. Manuscript drafting: ZZ, HJJ. Manuscript editing and revision: LS, HJH. Manuscript final version approval: ZZ, QH, HJH. Guarantor of the review: HJJ, HJH.

\section{Funding}


The study is supported in part by a research grant from the Fundamental Research Funds for the Central Universities (project No.2016YXMS111), and 2017 Teaching Research Project of Huazhong University of Science and Technology (project No.105).

\section{Availability of data and materials}

All relevant data for this study are presented in tables, figures and supplementary materials.

\section{Ethics approval and consent to participate}

Not applicable.

\section{Consent for publication}

Not applicable.

\section{Competing interests}

The authors declare that they have no competing interests.

\section{Abbreviations}

COVID-19: Coronavirus disease 2019; SARS-CoV-2: Severe acute respiratory syndrome coronavirus 2; MD: Mean difference; IQR: Interquartile range; IL-2: interleukin-2; IL-4: Interleukin-4; IL-5: Interleukin-5; IL-6: Interleukin-6; IL-10: Interleukin-10; TNF-a: Tumor necrosis factor alpha; IFN-ү: Interferon gamma; NK cell: Natural killer cell; Cl: Confidence interval; NOS: Newcastle-ottawa scale; ARDS: Acute respiratory distress syndrome; SD, Standard deviation; GM-CSF: Granulocyte-macrophage colony-stimulating factor; RANTES (CCL5): Regulated upon activation, normal T-cell expressed and secreted; IP-10 (CXCL10): IFN-ץ Inducible protein-10; MCP-1 (CCL2): Monocyte chemoattractant protein-1.

\section{References}

1. Huang C, Wang Y, Li X, Ren L, Zhao J, Hu Y, et al. Clinical features of patients infected with 2019 novel coronavirus in Wuhan, China. Lancet. 2020;395:497-506. doi:10.1016/S0140-6736(20)301835 .

2. World Health Organization. Coronavirus disease (COVID-19). Weekly Operational Update [accessed 9 September 2020]. Available from: https://www.who.int/docs/default-source/coronaviruse/weeklyupdates/wou-9-september-2020-cleared-14092020.pdf?sfvrsn=68120013_2.

3. Chen G, Di Wu, Guo W, Cao Y, Huang D, Wang H, et al. Clinical and immunological features of severe and moderate coronavirus disease 2019. J Clin Invest. 2020;130:2620-9. doi:10.1172/JCl137244.

4. Qin C, Zhou L, Hu Z, Zhang S, Yang S, Tao Y, et al. Dysregulation of immune response in patients with COVID-19 in Wuhan, China. Clin Infect Dis 2020. doi:10.1093/cid/ciaa248. 
5. Hue S, Beldi-Ferchiou A, Bendib I, Surenaud M, Fourati S, Frapard T, et al. Uncontrolled Innate and Impaired Adaptive Immune Responses in Patients with COVID-19 ARDS. Am J Respir Crit Care Med 2020. doi:10.1164/rccm.202005-18850C.

6. He R, Lu Z, Zhang L, Fan T, Xiong R, Shen X, et al. The clinical course and its correlated immune status in COVID-19 pneumonia. Journal of clinical virology : the official publication of the Pan American Society for Clinical Virology. 2020;127:104361. doi:10.1016/j.jcv.2020.104361.

7. Zhao Y, Qin L, Zhang P, Li K, Liang L, Sun J, et al. Longitudinal COVID-19 profiling associates IL-1RA and IL-10 with disease severity and RANTES with mild disease. JCI Insight 2020. doi:10.1172/jci.insight.139834.

8. Hozo SP, Djulbegovic B, Hozo I. Estimating the mean and variance from the median, range, and the size of a sample. BMC Med Res Methodol. 2005;5:13. doi:10.1186/1471-2288-5-13.

9. Du R-H, Liang L-R, Yang C-Q, Wang W, Cao T-Z, Li M, et al. Predictors of mortality for patients with COVID-19 pneumonia caused by SARS-CoV-2: a prospective cohort study. Eur Respir J 2020. doi:10.1183/13993003.00524-2020.

10. Chen R, Sang L, Jiang M, Yang Z, Jia N, Fu W, et al. Longitudinal hematologic and immunologic variations associated with the progression of COVID-19 patients in China. J Allergy Clin Immunol 2020. doi:10.1016/j.jaci.2020.05.003.

11. Jiang M, Guo Y, Luo Q, Huang Z, Zhao R, Liu S, et al. T cell subset counts in peripheral blood can be used as discriminatory biomarkers for diagnosis and severity prediction of COVID-19. The Journal of infectious diseases 2020. doi:10.1093/infdis/jiaa252.

12. Liu Y, Liao W, Wan L, Xiang T, Zhang W. Correlation Between Relative Nasopharyngeal Virus RNA Load and Lymphocyte Count Disease Severity in Patients with COVID-19. Viral Immunol 2020. doi:10.1089/vim.2020.0062.

13. Ma J, Yin J, Qian Y, Wu Y. Clinical characteristics and prognosis in cancer patients with COVID-19: A single center's retrospective study. The Journal of infection 2020. doi:10.1016/j.jinf.2020.04.006.

14. Sun D-W, Zhang D, Tian R-H, Li Y, Wang Y-S, Cao J, et al. The underlying changes and predicting role of peripheral blood inflammatory cells in severe COVID-19 patients: a sentinel? Clin Chim Acta 2020. doi:10.1016/j.cca.2020.05.027.

15. Wan S, Yi Q, Fan S, Lv J, Zhang X, Guo L, et al. Relationships among lymphocyte subsets, cytokines, and the pulmonary inflammation index in coronavirus (COVID-19) infected patients. Br J Haematol. 2020;189:428-37. doi:10.1111/bjh.16659.

16. Wang F, Yang Y, Dong $K$, Yan Y, Zhang S, Ren H, et al. CLINICAL CHARACTERISTICS OF 28 PATIENTS WITH DIABETES AND COVID-19 IN WUHAN, CHINA. Endocr Pract 2020. doi:10.4158/EP-2020-0108.

17. Zhang J, Yu M, Tong S, Liu L-Y, Tang L-V. Predictive factors for disease progression in hospitalized patients with coronavirus disease 2019 in Wuhan, China. Journal of clinical virology : the official publication of the Pan American Society for Clinical Virology. 2020;127:104392.

doi:10.1016/j.jcv.2020.104392. 
18. Zheng Y, Xu H, Yang M, Zeng Y, Chen H, Liu R, et al. Epidemiological characteristics and clinical features of 32 critical and 67 noncritical cases of COVID-19 in Chengdu. Journal of clinical virology : the official publication of the Pan American Society for Clinical Virology. 2020;127:104366. doi:10.1016/j.jcv.2020.104366.

19. Zhou Y, Zhang Z, Tian J, Xiong S. Risk factors associated with disease progression in a cohort of patients infected with the 2019 novel coronavirus. Ann Palliat Med. 2020;9:428-36. doi:10.21037/apm.2020.03.26.

20. Zhu Z, Cai T, Fan L, Lou K, Hua X, Huang Z, Gao G. Clinical value of immune-inflammatory parameters to assess the severity of coronavirus disease 2019. Int J Infect Dis. 2020;95:332-9. doi:10.1016/j.ijid.2020.04.041.

21. Pallotto C, Suardi LR, Esperti S, Tarquini R, Grifoni E, Meini S, et al. Increased CD4/CD8 ratio as a risk factor for critical illness in coronavirus disease 2019 (COVID-19): a retrospective multicentre study. Infectious Diseases. 2020;52:675-7. doi:10.1080/23744235.2020.1778178.

22. Urra JM, Cabrera CM, Porras L, Ródenas I. Selective CD8 cell reduction by SARS-CoV-2 is associated with a worse prognosis and systemic inflammation in COVID-19 patients. Clinical Immunology 2020. doi:10.1016/j.clim.2020.108486.

23. Li S, Jiang L, Li X, Lin F, Wang Y, Li B, et al. Clinical and pathological investigation of patients with severe COVID-19. JCI Insight 2020. doi:10.1172/jci.insight.138070.

24. Chi Y, Ge Y, Wu B, Zhang W, Wu T, Wen T, et al. Serum Cytokine and Chemokine Profile in Relation to the Severity of Coronavirus Disease 2019 in China. The Journal of infectious diseases. 2020;222:746-54. doi:10.1093/infdis/jiaa363.

25. Rogers MC, Lamens KD, Shafagati N, Johnson M, Oury TD, Joyce S, Williams JV. CD4+ Regulatory T Cells Exert Differential Functions during Early and Late Stages of the Immune Response to Respiratory Viruses. J Immunol. 2018;201:1253-66. doi:10.4049/jimmunol.1800096.

26. Yang M, Li CK, Li K, Hon KLE, Ng MHL, Chan PKS, Fok TF. Hematological findings in SARS patients and possible mechanisms (review). Int J Mol Med. 2004;14:311-5.

27. Zhang J, Yu M, Tong S, Liu L-Y, Tang L-V. Predictive factors for disease progression in hospitalized patients with coronavirus disease 2019 in Wuhan, China. Journal of clinical virology : the official publication of the Pan American Society for Clinical Virology. 2020;127:104392. doi:10.1016/j.jcv.2020.104392.

28. Moore JB, June CH. Cytokine release syndrome in severe COVID-19. Science. 2020;368:473-4. doi:10.1126/science.abb8925.

29. Jones SA, Jenkins BJ. Recent insights into targeting the IL- 6 cytokine family in inflammatory diseases and cancer. Nat Rev Immunol. 2018;18:773-89. doi:10.1038/s41577-018-0066-7.

30. Gupta S, Bi R, Kim C, Chiplunkar S, Yel L, Gollapudi S. Role of NF-kappaB signaling pathway in increased tumor necrosis factor-alpha-induced apoptosis of lymphocytes in aged humans. Cell Death Differ. 2005;12:177-83. doi:10.1038/sj.cdd.4401557. 
31. Diao B, Wang C, Tan Y, Chen X, Liu Y, Ning L, et al. Reduction and Functional Exhaustion of T Cells in Patients With Coronavirus Disease 2019 (COVID-19). Front Immunol. 2020;11:827. doi:10.3389/fimmu.2020.00827.

32. Costela-Ruiz VJ, Illescas-Montes R, Puerta-Puerta JM, Ruiz C, Melguizo-Rodríguez L. SARS-CoV-2 infection: The role of cytokines in COVID-19 disease. Cytokine Growth Factor Rev 2020. doi:10.1016/j.cytogfr.2020.06.001.

33. Shi C, Pamer EG. Monocyte recruitment during infection and inflammation. Nat Rev Immunol. 2011;11:762-74. doi:10.1038/nri3070.

\section{Tables}


Table 1. Main characteristics and quality of the included studies.

\begin{tabular}{|c|c|c|c|c|c|c|c|}
\hline Author & Study Design & Country & Age (years) & $\begin{array}{l}\text { Sample size } \\
\text { (Severe) }\end{array}$ & $\begin{array}{l}\text { Sample size } \\
\text { (Mild) }\end{array}$ & $\begin{array}{l}\text { Sample } \\
\text { size }\end{array}$ & $\begin{array}{l}\text { Sex (male } \\
\%)\end{array}$ \\
\hline Chen G. 2020 [3] & Retrospective & China & $56(50-65)$ & 11 & 10 & 21 & $17(81 \%)$ \\
\hline Chen R. 2020 [10] & Retrospective & China & $56 \pm 15$ & 155 & 345 & 500 & $313(57.1 \%)$ \\
\hline Du R. 2020 [9] & Prospective & China & $69 \pm 8$ & 21 & 42 & 63 & $30(47.6 \%)$ \\
\hline He R. 2020 [6] & Retrospective & China & $49(34-62)$ & 69 & 135 & 204 & $79(38.7 \%)$ \\
\hline Jiang M. 2020 [11] & Retrospective & China & $46(17-88)$ & 17 & 86 & 103 & $58(56.3 \%)$ \\
\hline Liu Y. 2020 [12] & Retrospective & China & 1 & 30 & 46 & 76 & 1 \\
\hline Ma J. 2020 [13] & Retrospective & China & $62(59-70)$ & 17 & 20 & 37 & $20(54 \%)$ \\
\hline Qin C. 2020 [4] & Retrospective & China & $58(47-67)$ & 27 & 17 & 44 & $235(52 \%)$ \\
\hline Sun D. 2020 [14] & Retrospective & China & 65 & 11 & 25 & 36 & $29(80.5 \%)$ \\
\hline Wan S. 2020 [15] & Retrospective & China & 46 & 21 & 102 & 123 & $66(53.7 \%)$ \\
\hline Wang F. 2020 [16] & Retrospective & China & $69 \pm 9$ & 14 & 14 & 28 & $21(75 \%)$ \\
\hline Zhang J. 2020 [17] & Retrospective & China & $38(32-57)$ & 93 & 18 & 111 & $46(41.4 \%)$ \\
\hline Zheng Y. 2020 [18] & Retrospective & China & 49 & 26 & 63 & 89 & / \\
\hline Zhou Y. 2020 [19] & Retrospective & China & 42 & 5 & 12 & 17 & $6(35.3 \%)$ \\
\hline Zhu Z. $2020[20]$ & Retrospective & China & 51 & 111 & 16 & 127 & $45(35.4 \%)$ \\
\hline Pallotto C. 2020 [21] & Retrospective & Italy & 65 & 13 & 25 & 38 & $19(50.0 \%)$ \\
\hline Urra J.M. 2020 [22] & Retrospective & Spain & 59 & 27 & 145 & 172 & $104(60.5 \%)$ \\
\hline Sophie H. 2020 [5] & Retrospective & France & 66 & 38 & 36 & 74 & $60(81.1 \%)$ \\
\hline Li S. $2020[23]$ & Retrospective & China & 46 & 26 & 43 & 69 & $40(60.0 \%)$ \\
\hline Zhao Y. 2020 [7] & Retrospective & China & 48 & 18 & 53 & 71 & $30(42.3 \%)$ \\
\hline Chi Y. $2020[24]$ & Retrospective & China & 46 & 8 & 22 & 30 & 1 \\
\hline
\end{tabular}

Age is described as mean or mean $\pm \mathrm{SD}$ or median (IQR).

Table 2. Newcastle-Ottawa Scale (NOS) of included studies

\begin{tabular}{|c|c|c|c|c|c|c|c|c|c|}
\hline Included studies & $\begin{array}{l}\text { Is the } \\
\text { definition } \\
\text { adequate? }\end{array}$ & $\begin{array}{l}\text { Represent } \\
\text { activeness of } \\
\text { the eases }\end{array}$ & \begin{tabular}{|l|} 
Selection of \\
controls
\end{tabular} & \begin{tabular}{|l|} 
Definition \\
of controls
\end{tabular} & $\begin{array}{l}\text { Comparability } \\
\text { of both groups }\end{array}$ & \begin{tabular}{|l|} 
Ascertainment of \\
diagnosis
\end{tabular} & $\begin{array}{l}\text { Same ascertainment } \\
\text { me thod for both } \\
\text { groups }\end{array}$ & $\begin{array}{l}\text { Nonresponse } \\
\text { rate }\end{array}$ & $\begin{array}{l}\text { Total } \\
\text { scores }\end{array}$ \\
\hline Cben G. 2020 [3] & मे & मे & 会 & 삭 & मे & मे & 它 & 会 & 8 \\
\hline Cben R $2020[10]$ & मे & $\frac{1}{4}$ & $\hat{\nu}$ & 放 & $\overrightarrow{\dot{H}}$ & 它 & मे & $\hat{s}$ & 8 \\
\hline Du R. 2020 [9] & मे & $\frac{1}{x}$ & $\hat{\nu}$ & रे & $\vec{H}$ & 安 & 핳 & 樎 & 8 \\
\hline He R. 2020 [6] & $\vec{r}$ & मे & 喵 & 성 & मे & 삼 & 상 & 喵 & 8 \\
\hline Fung M. 2020 [11] & मे & $\frac{1}{42}$ & 论 & 众 & मे & मे & 曻 & 论 & 8 \\
\hline Lin Y. 2020 [12] & मे & $\frac{1}{42}$ & 貉 & मे & 7 & मे & मे & 客 & 7 \\
\hline Ma J. 2020 [13] & मे & मs & $\hat{\Delta}$ & st & 全话 & 今े & 핳 & $\hat{s}$ & 9 \\
\hline Qin C. 2020 [4] & $\frac{1}{4}$ & 安 & 话 & 성 & $\vec{r}$ & 항 & $\hat{\Delta}$ & $\hat{s}$ & 8 \\
\hline Sun D. $2020[14]$ & मे & मे & $\hat{\Delta}$ & 섭 & मे & 학 & 홯 & $\hat{s}$ & 8 \\
\hline Wan S. 2020 [15] & $\dot{म}$ & 安 & $\hat{\nu}$ & मे & $\dot{\vec{r}}$ & 삼 & $\Delta$ & 诺 & 8 \\
\hline Wang F. 2020 [16] & मे & $\frac{1}{x}$ & 问 & मे & 众话 & 상 & मे & $\hat{\gamma}$ & 9 \\
\hline Zhang 1. 2020 [17] & मे & मे & 貉 & मे & मे & 항 & 今े & 它 & 9 \\
\hline Zheng Y. 2020 [18] & मे & मे & $\hat{\imath}$ & st & मे & 삼 & $\Delta$ & 谣 & 8 \\
\hline Zhou Y. 2020 [19] & $\vec{r}$ & $\frac{1}{4}$ & 徣 & 安 & मे & st & 众 & $\hat{\psi}$ & 8 \\
\hline $\operatorname{Znz} 2020$ [20] & मे & मे & 全 & 삽 & $\overrightarrow{4}$ & 섬 & 항 & 店 & 8 \\
\hline Palbtis C. $2020[21]$ & मे & 名 & 埌 & 항 & 它它 & मे & मे & 徣 & 9 \\
\hline Uma J.M. 2020 [22] & मे & $\frac{1}{42}$ & 话 & मे & 众话 & मे & 实 & 貉 & 9 \\
\hline Sophie IL 2020 [5] & मे & मे & $\hat{\imath}$ & 상 & 穴话 & के & 석 & 谣 & 9 \\
\hline LSS. 2020 [23] & 安 & मे & $\hat{\gamma}$ & 상 & 它说 & 삭 & 삭 & 谓 & 9 \\
\hline Zhao Y. 2020 [7] & मे & मे & $\hat{\nu}$ & 삭 & 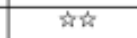 & 석 & 학 & 它 & 9 \\
\hline CHYY. 2020 [24] & मे & $\frac{1}{4}$ & $\hat{\gamma}$ & 섭 & $\vec{r}$ & 색 & मे & 诺 & 8 \\
\hline
\end{tabular}

\section{Figures}




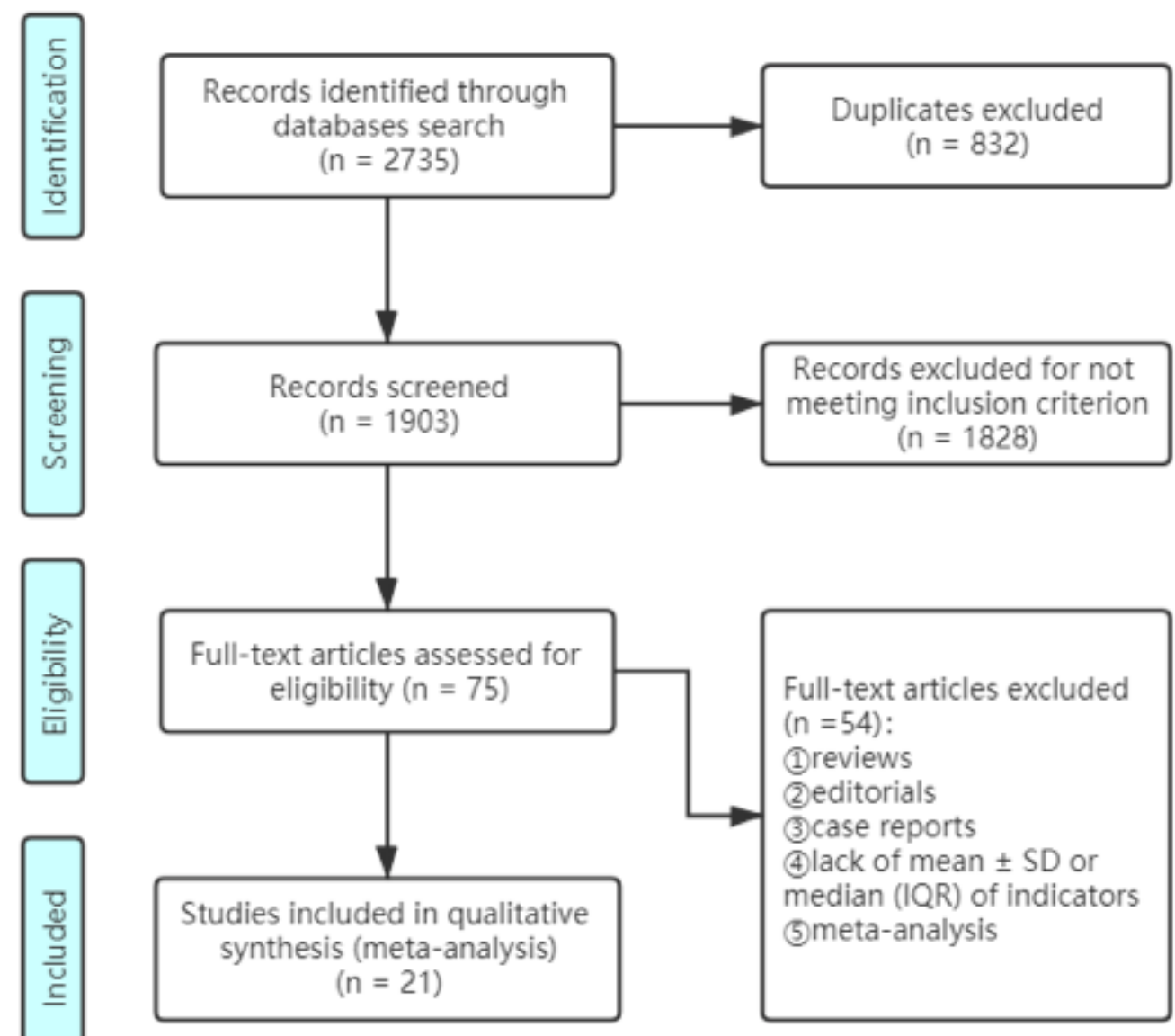

Figure 1

Flow diagram for studies selection 


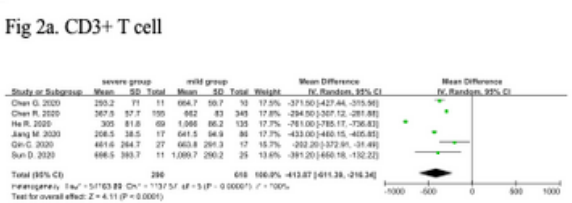

Fig 2b. CD4+ T cell

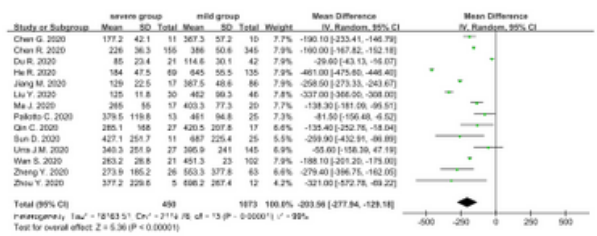

Fig 2c. CD8+ T cell

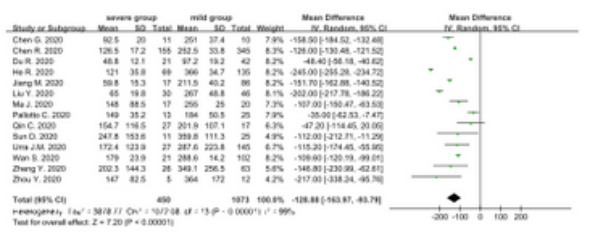

Fig 2d. CD4+/CD8+ ratio

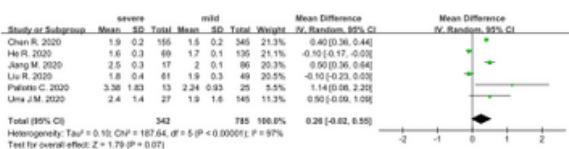

Fig 2e. Treg cell

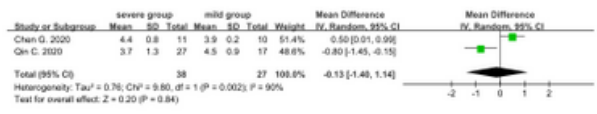

Fig $2 f$. B cell

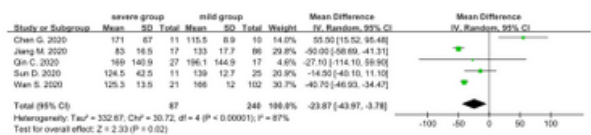

Fig 2g. NK cell

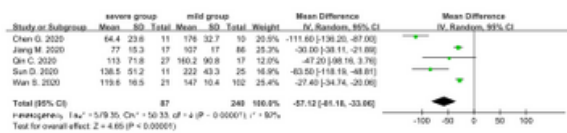

Fig 2h. TNF- $\alpha$

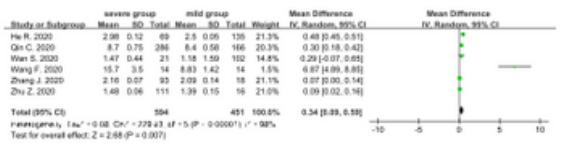

Fig 2i. IFN- $\gamma$

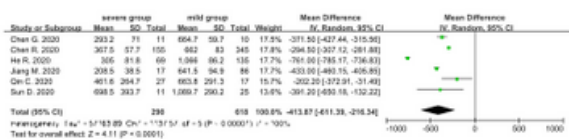

Fig 2j. IL-2

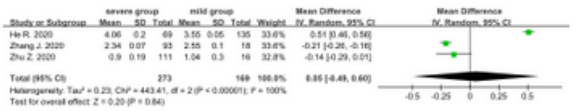

Fig 2k. IL-4

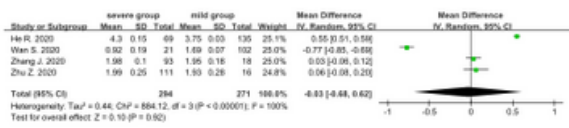

Fig 21. IL-5

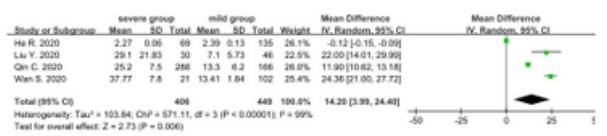

Fig $2 \mathrm{~m}$. IL-6

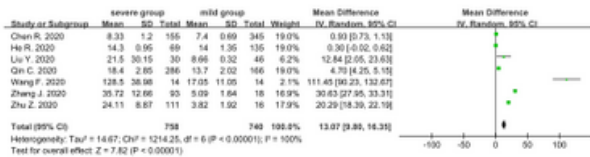

Fig 2n. IL-10

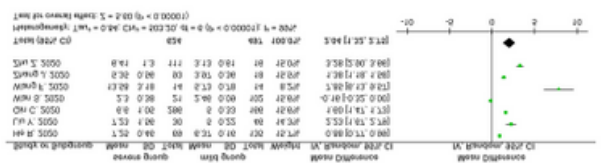

Fig 20. GM-CSF

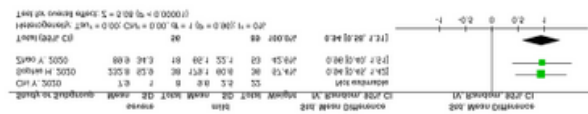

Fig 2p. RANTES

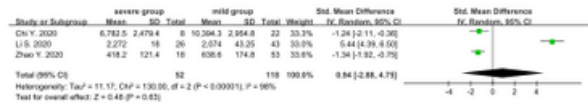

Fig 2q. MCP-1

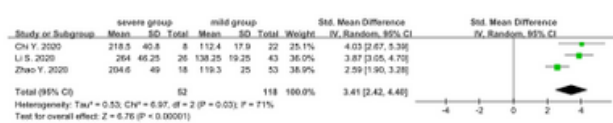

Fig 2r. IP-10

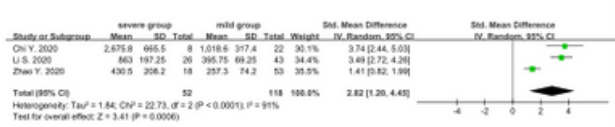

Fig 2s. Eotaxin

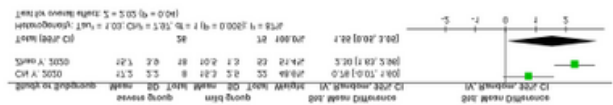

\section{Figure 2}

Mean difference of immunological features with COVID-19 severity. 
Fig 3a. CD3+ T cell

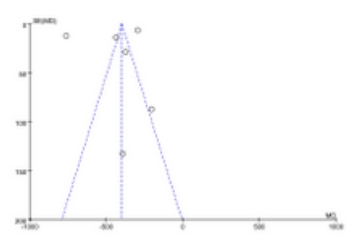

Fig 3b. CD4+ T cell

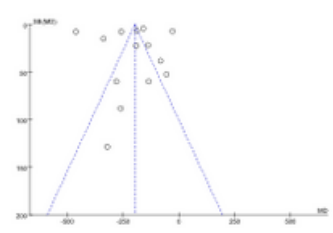

Fig 3c. CD8+ T cell

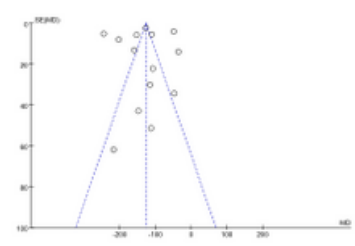

Fig 3d. CD4+/CD8+ ratio

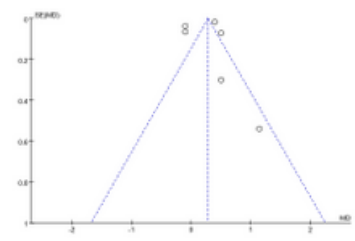

Fig 3e. Treg cell

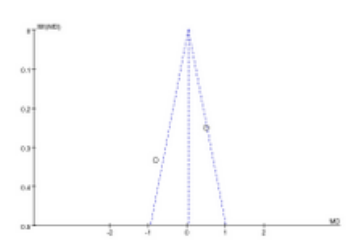

Fig 3f. B cell

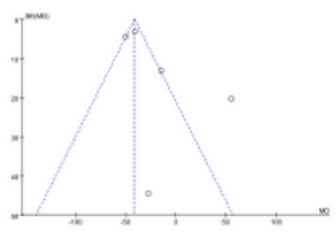

Fig 3g. NK cell

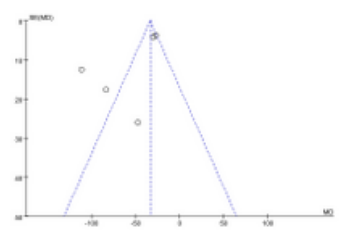

Fig 3 h. TNF- $\alpha$

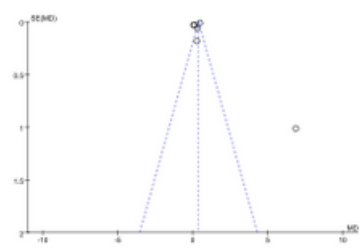

Fig 3i. IFN- $\gamma$

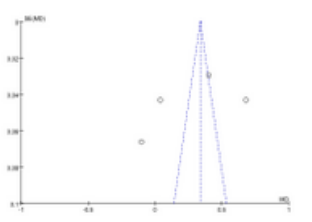

Fig 3j. IL-2

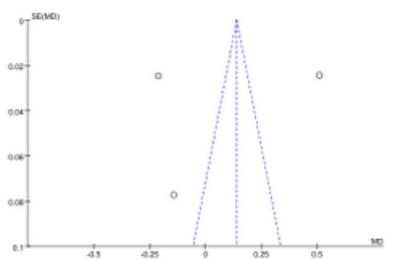

Fig 3k. IL-4

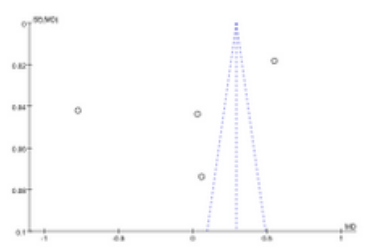

Fig 31. IL-5

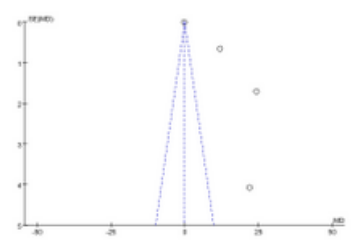

Fig 3m. IL-6

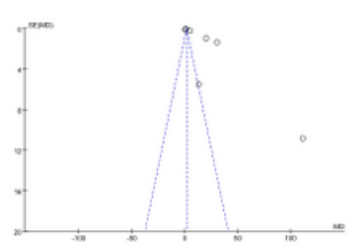

Fig 3n. IL-10

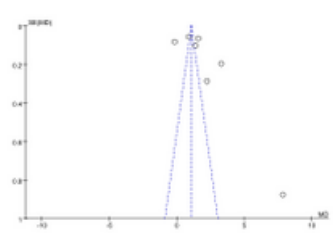

Fig 3o. GM-CSF

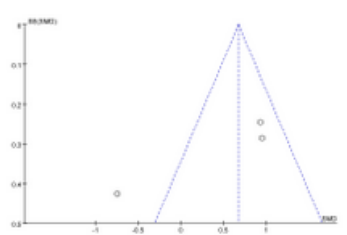

Fig 3p. RANTES

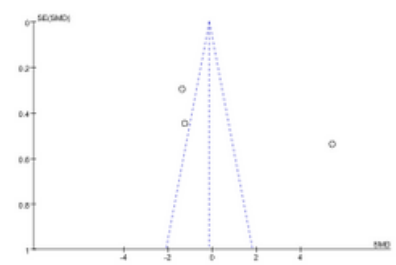

Fig 3q. MCP-1

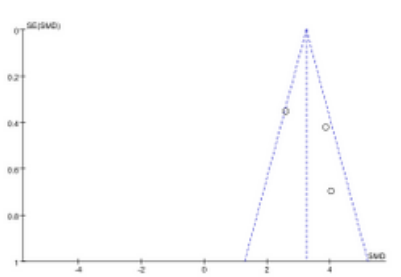

Fig 3r. IP-10

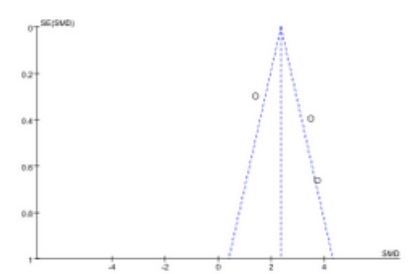

Fig 3s. Eotaxin

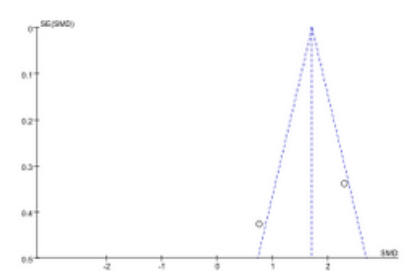

Figure 3

Funnel plots of immunological features with COVID-19 severity. 